\title{
Penilaian Kompetisi dan Keuntungan Hasil Tumpangsari Jagung Kedelai di Bawah Tegakan Kayu Putih
}

\author{
Syprianus Ceunfin ${ }^{a}$, Djoko Prajitno $^{b}$, Priyono Suryanto ${ }^{c}$, Eka Tarwaca Susila Putra ${ }^{b}$ \\ ${ }^{a}$ Fakultas Pertanian, Universitas Timor, Kefamenanu, TTU - NTT, Indonesia. \\ ${ }^{b}$ Fakultas Pertanian, Universitas Gadjah Mada, Jogyakarta, Indonesia. \\ ${ }^{c}$ Fakultas Kehutanan, Universitas Gadjah Mada, Jogyakarta, Indonesia.
}

Article Info

Article history:

Received 25 Oktober 2016

Received in revised form 28 November 2016 Accepted 5 Januari 2017

\section{Keywords:}

\section{Jagung}

Kedelai

Tumpangsari

Kompetisi

\begin{abstract}
Abstrak
Penelitian ini bertujuan untuk mengetahui nilai kompetisi dan keuntungan hasil dalam tumpangsari jagung varietas pioner 21 dan kedelai varietas grobogan dibawah tegakan hutan kayu putih. Penelitian ini menggunakan metode percobaan lapangan yang terdiri atas dua faktor dan dirancang dengan menggunakan Rancangan Petak ber-alur. Faktor pertama sebagai petak utama berupa Posisi bidang olah dari kedudukan tegakan kayu putih (Zona) dan faktor kedua sebagai anak petak adalah jarak tanam jagung. Petak utama berupa zona bidang olah terdiri dari 2 aras yaitu zona 1 terletak pada posisi bidang olah yang berjarak 0-1 m dari kedudukan tegakan (Z1); zona 2 terletak pada posisi bidang olah yang berjarak 1-2 m dari kedudukan tegakan (Z2), Anak petak adalah jarak tanam jagung yang terdiri atas 3 aras yaitu: $50 \mathrm{~cm} \times 20 \mathrm{~cm}(\mathrm{~J} 1), 70 \mathrm{~cm} \times 20 \mathrm{~cm}(\mathrm{~J} 2)$ dan $90 \mathrm{~cm} \times 20 \mathrm{~cm}(\mathrm{~J} 3)$. Hasil penelitian menunjukkan bahwa Tumpangsari tanaman jagung dan kedelai dibawah tegakan kayu putih sangat menguntungkan. Tanaman jagung lebih agresif dan competitif daripada tanaman kedelai sehingga menyumbangkan keuntungan pada land equivalent ratio total dan area time equivalent ratio dan Actual Yeild loss total pada perlakuan zona pengolahan lahan maupun jarak tanaman. Zona pengolahan lahan 0-1 m dari kedudukan pohon kayu putih memberikan hasil land equivalent ratio total, area time equivalent ratio, dan actual yield loss total paling tinggi yaitu sebesar 1,71, 1,66 dan 0,82 sedangkan Jarak tanam $50 \mathrm{~cm} \times 20 \mathrm{~cm}$ memberikan hasil land equivalent ratio total, area time equivalent ratio, dan actual yield loss total paling tinggi yaitu sebesar 2,27, 2,25 dan 1,58. C2017 dipublikasikan oleh Savana Cendana.
\end{abstract}

\section{Pendahuluan}

Rendahnya produktivitas lahan agroforestri adalah selain adanya kompetisi akan sumberdaya, juga disebabkan oleh sistem pertanaman. Sistem pertanaman yang sering dilakukan dalam lahan agroforestri adalah sistem tanam monokultur tanaman semusim. Hal ini tentunya membutuhkan input sumberdaya yang terus meningkat pada setiap musim tanam. Untuk mengurangi input sumberdaya maka perlu ada perubahan sistem pertanaman dalam areal pertanaman. Perubahan yang dimaksud adalah dengan menanam lebih dari satu tanaman semusim yang berbeda namun saling memberi keuntungan. Pola pertanaman ganda yang biasa dilakukan oleh petani adalah Sistem bertanam tumpangsari (intercropping) yaitu penanaman lebih dari satu jenis tanaman berumur genjah dalam barisan tanaman yang teratur yang dilakukan secara besamaan pada lahan yang sama.

Tumpangsari adalah penanaman dua atau lebih jenis tanaman secara berdekatan pada lahan yang sama dan terdapat interaksi diantara tanaman tersebut. Sistem ini dilakukan untuk meningkatkan potensi lahan dan produksi hasil tanaman dan lebih produktif dibandingkan dengan sistem monokultur, terutama pada kondisi yang kurang baik serta menekan aktivitas hama dengan meningkatnya diversitas tanaman pada pola pertanaman ini (Karyawati et al., 2010).

Pada umumnya sistem tumpangsari lebih menguntungkan dibanding sistem monokultur karena produksivitas lahan menjadi lebih tinggi, jenis komoditas yang dihasilkan beragam, hemat dalam pemakaian sarana produksi dan resiko kegagalan dapat diperkecil (Turmudi, 2002). Disamping keuntungan diatas sistem tumpangsai dapat digunakan sebagai alat untuk konservasi lahan (Anil et al, 1998), pengendalian gulma (Poggio, 2005; Banik et al. 2006), pengendalian hama dan penyakit tanaman (Anil et al., 1998), meningkatkan hasil tanaman (Anil et al, 1998;. Chen et al, 2004) bahkan cara ini dapat mempertahankan kesuburan tanah bila salah satu jenis tanaman adalah tanaman legumenocea yang ditumpangsarikan dalam lahan (Yilmaz et al.,2008). Di daerah yang menerima curah hujan yang rendah untuk waktu yang singkat, petani sangat tergantung pada curah hujan, untuk produksi harus menanam kultivar musim pendek pada tumpangsari. Penanaman komponen tanaman genjah pada awal musim hujan menjadi aspek penting bagi petani untuk meningkatkan produktivitas (Egbe, 2010) waktu tanam yang tepat dari spesies tumpangsari mengarah ke produksi yang tinggi karena berkurangnya persaingan di antara tanaman (Makgoga, 2013).

Distribusi akar tanaman baik tanaman pohon maupun tanaman semusim memiliki jangkauan yang berbeda-beda dalam mencapai hara dan air. Tanaman pohon tentu memiliki jangkauan yang lebih luas dan dalam dibandingkan tanaman semusim. Hal ini berhubungan erat dengan zona pengolahan lahan pada sistem agroforestri. Semakin dekat zona pengolahan lahan untuk tanaman semusim dengan tegakan tanaman pohon ada kecendrungan tanaman semusim mengalami tekanan kekurangang hara maupun air. Sistem berbagi sumberdaya dalam sistem agroforestri awal menunjukkan bahwa pada zona 1 (pemanfaatan energi didominasi oleh pohon/tanaman semusim sangat tertekan), zona 2 (respon tanaman semusim tertekan) dan pada zona 3 (respon tanaman semusim optimal) (Suryanto, et al., 2005)

Selain faktor zona pengolahan lahan, input teknologi perlu diperhatikan, salah satunya adalah jarak tanam. Jarak tanam rapat akan mengakibatkan tanaman saling bersaing dalam memperebutkan sumberdaya seperti hara, air maupun cahaya matahari sehingga hasil fotosintesis lebih banyak digunakan untuk memenuhi kebutuhan daun yang ternaungi dibandingkan dengan penyimpanan hasil fotosintesis, sebaliknya jarak tanam yang terlampau longgar bisa saja menurunkan hasil tanaman karena jumlah populasi tanaman per satuan luas lahan sangat sedikit.

Permasahannya adalah belum diketahui nilai kompetisi dan keuntungan hasil tumpangsari jagung dan kedelai dibawah tegakan kayu putih pada zona pengolahan lahan dan jarak tanam, sehingga penelitian ini bertujuan untuk mengetahui nilai kompetisi dan keuntungan hasil dalam tumpangsari.

\section{Metode}

Penelitian ini dilaksanakan di RPH Menggoran, Desa Bleberan, Kecamatan Playen, Kabupaten Gunung Kidul, Yogyakarta pada bulan Oktober 2014 - Maret 2015. Penelitian ini dilaksanakan dengan menggunakan metode percobaan lapangan yang terdiri atas dua faktor dan dirancang dengan menggunakan Rancangan Petak ber-alur (Strip Plot). Faktor pertama sebagai petak utama (main plot) berupa Posisi bidang olah dari kedudukan tegakan kayu putih (Zona) dan faktor kedua sebagai anak petak (sub plot) adalah jarak tanam jagung. Petak utama berupa zona bidang olah terdiri dari 2 aras yaitu zona 1 terletak pada posisi bidang olah yang berjarak 0-1 m dari kedudukan tegakan (Z1); zona 2 terletak pada posisi bidang olah yang berjarak 1-2 m dari kedudukan tegakan (Z2), Anak petak adalah jarak tanam jagung yang terdiri atas 3 aras yaitu: $50 \mathrm{~cm} \times 20 \mathrm{~cm}$ (J1), $70 \mathrm{~cm}$ x $20 \mathrm{~cm}(\mathrm{~J} 2)$ dan $90 \mathrm{~cm}$ x $20 \mathrm{~cm}(\mathrm{~J} 3)$. Parameter yang diamati antara lain:

Land Equivalent Ratio merupakan gambaran efisiensi penggunaan lahan. Nilai kesetaraan lahan dapat dihitung pada saat tanaman sudah dipanen. Perhitungan dilakukan pada hasil jagung intercropping (Yab), hasil jagung monocropping (Yaa), hasil kacang intercropping (Yba), dan hasil kacang monocropping (Ybb). Nisbah kesetaraan lahan dapat dihitung untuk mengetahui tingkat efisiensi lahan dalam sistem tumpangsari yang dicobakan. Menurut Beets (1982) LER dapat dihitung dengan menggunakan rumus:

$$
\mathrm{LER}=\frac{Y a b}{Y a a}+\frac{Y b a}{Y b b}
$$

\section{b. Area Time Equivalent Ratio (ATER)}

Area Time Equivalent Ratio (ATER) adalah gambaran nilai kesetaraan lahan berdasarkan waktu. Keuntungan hasil per satuan lahan juga dipengaruhi oleh waktu tanam maupun waktu panen dalam tumpangsari. Semakin lama suatu jenis tanaman berada dalam lahan maka keuntungan hasil dari sisi waktu semakin kecil. Area time equivalent ratio dapat dihitung menggunakan rumus yang diperkenalkan oleh Beets (1982) sebagai berikut:

$$
\mathrm{ATER}=\frac{\frac{Y a b}{A a b \times T a b}}{\frac{Y a a}{A a a / T a a}}+\frac{\frac{Y b a}{A b a \times T}}{\frac{Y b b}{A b b \times T b a}}
$$

Dimana: hasil jagung intercropping (Yab), hasil jagung monocropping (Yaa), hasil kacang intercropping (Yba), hasil kacang monocropping (Ybb), luas lahan (A), dan Waktu yang dibutuhkan sampai panen (T)

\section{c. Relative Crowding Coefficient (K)}

Kepadatan tanaman dalam tumpangsari adalah proporsi atau jumlah tanaman yang menempati suatu unit lahan pada waktu dan tempat yang sama dan mampu memberikan hasil optimum pada masing-masing jenis tanaman yang ditumpangsarikan. Koefisien kepadatan relatif dapat di hitung menggunakan rumus yang diperkenalkan oleh Palaniappan (1985):

$$
K a b=\frac{\mathrm{Yab} \times \mathrm{Zba}}{(\mathrm{Yaa}-\mathrm{Yab}) \times \mathrm{Zab}}
$$

a. Land Equivalent Ratio (LER) 
Dimana: hasil intercropping (Yab), hasil monocropping (Yaa), Proporsi tanaman $\mathrm{b}$ dalam intercropping (Zba), proporsi tanaman a dalam intercropping $(\mathrm{Zab})$

\section{d. Aggresivity (A)}

Kompetisi dalam tumpangsari selalu terjadi baik antar tanaman maupun antar spesies tanaman yang ditumpangsarikan. Agresivitas digunakan untuk mengukur kemampuan berkompetisi dalam memperoleh sumberdaya pada sistem tumpangsari. Nilai Agresivitas dapat dihitung mengunakan rumus yang diperkenalkan oleh Palaniappan (1985):

$$
A a b=\frac{Y a b}{\mathrm{Yaa}-\mathrm{Zab}}-\frac{\mathrm{Yba}}{Y b b-\mathrm{Z} b a}
$$

Dimana: hasil tanaman a dalamintercropping (Yab), hasil tanaman $\mathrm{b}$ dalamintercropping (Yba), hasil monocropping tanaman a (Yaa), hasil monocropping tanaman $b$ (Ybb), Proporsi tanaman b dalam intercropping ( $\mathrm{Zba}$ ), proporsi tanaman a dalam intercropping ( $\mathrm{Zab})$.

\section{e. Competitive Ratio (CR)}

Ratio kompetisi adalah ratio LER individu pada masing-masing komponen tanaman dengan memperhitukan proporsi tanaman yang telah ditanaman dalam tumpangsari pada awal penanaman (Yilmaz et al., 2011). Nilai ratio kompetisi dapat dihitung menggunakan rumus matematika (Palaniappan,1985) sebagai berikut:

$$
C R=\frac{Y a b / Y a a}{Y b a / Y b b} \times \frac{Z b a}{Z a b} \text { atau } \frac{\mathrm{LER} \mathrm{a}}{\mathrm{LER} \mathrm{b}} \times \frac{\mathrm{Zba}}{\mathrm{Zab}}
$$

Dimana: hasil tanaman a dalamintercropping (Yab), hasil tanaman b dalamintercropping (Yba), hasil monocropping tanaman a (Yaa), hasil monocropping tanaman $b$ (Ybb), Proporsi tanaman b dalam intercropping ( $\mathrm{Zba}$ ), proporsi tanaman a dalam intercropping ( $\mathrm{Zab})$.

\section{f. Actual Yeild Loss (AYL)}

Kehilangan hasil aktual adalah proporsi kehilangan hasil atau keuntungan tanaman sela yang ditanaman secara tumpangsari bila dibandikan dengan masing-masing tanaman monokultur (Yilmaz et al, 2011). Kehilang hasil pada tumpangsari diakibatkan oleh adanya kompetisi terhadap sumberdaya yang dibutuhkan untuk memenuhi kebutuhan hidup tanaman. Nilai kehilangan hasil aktual dapat dicari menggunakan rumus matematika sebagai berikut (Banik et al., 1996; Yilmaz et al., 2011):

$$
A Y L a b=(\mathrm{Yab} / \mathrm{Xab}) /(\mathrm{Yaa} / \mathrm{Xaa})-1
$$

Dimana: hasil tanaman a dalam intercropping (Yab), hasil monocropping tanaman a (Yaa), Proporsi tanaman a dalam intercropping (Xab), proporsi tanaman a dalam monokultur (Xaa).

\section{Hasil dan Pembahasan}

Efisiensi penggunaan lahan pada pola tumpang sari dapat dilihat melalui dua model persamaan yaitu Land Equivalent Ratio (LER) dan Area Time Equivalent Ratio (ATER). LER digunakan untuk memperkirakan pengaruh kompetisi dan keuntungan hasil dari sisi lahan sedangkan ATER digunakan untuk memperkirakan keuntungan hasil dari sisi waktu.

Hasil penelitian menunjukkan bahwa perlakuan jarak tanam $50 \mathrm{~cm} \times 20 \mathrm{~cm}$ memberikan hasil $L E R$ total dan ATER paling tinggi yang berbeda nyata dengan perlakuan jarak tanam lainnya sedangkan pada perlakuan zona ruang temu menunjukkan bahwa zona 1 lebih tinggi nilai $L E R$ dan ATER namun tidak berbeda nyata dengan zona ruang temu 2 (Tabel 1.). Hasil analisis terhadap LER dalam tumpangsari menunjukkan bahwa Hasil secara individu tanaman jagung memiliki nilai $L E R$ paling tinggi dibandingkan dengan hasil $L E R$ individu tanaman kedelai. Menurut Yilmaz et al. (2007) kenaikan hasil jagung umumnya merupakan konversi nitrogen yang hasilkan oleh tanaman kacang yang ditumpangsarikan dengan jagung serta sistem perakaran dan tajuk tanaman jagung yang memiliki jangkauan lebih luas.

Tabel 1. Land Equivalent Ratio dan Area Time Equivalent Ratio

\begin{tabular}{lcccc}
\hline \multirow{2}{*}{ Perlakuan } & \multicolumn{3}{c}{ Land Equivalent Ratio } & \multirow{2}{*}{$\begin{array}{c}\text { Area Time } \\
\text { Equivalent Ratio }\end{array}$} \\
\cline { 2 - 4 } Jarak Tanam & Jagung & Kedelai & Total & \\
\hline $50 \mathrm{~cm} \times 20 \mathrm{~cm}$ & $1,0472 \mathrm{a}$ & $0.5490 \mathrm{a}$ & $2,2788 \mathrm{a}$ & $2,2542 \mathrm{a}$ \\
$70 \mathrm{~cm} \times 20 \mathrm{~cm}$ & $1,0772 \mathrm{a}$ & $0.5684 \mathrm{a}$ & $1,4833 \mathrm{~b}$ & $1,4382 \mathrm{~b}$ \\
$90 \mathrm{~cm} \times 20 \mathrm{~cm}$ & $1,1620 \mathrm{a}$ & $0.6846 \mathrm{a}$ & $1,2751 \mathrm{~b}$ & $1,2205 \mathrm{~b}$ \\
\hline Zona Ruang Temu & & & & \\
\hline Zona 1 & $1,07973 \mathrm{a}$ & $0.6682 \mathrm{a}$ & $1,7104 \mathrm{a}$ & $1,6649 \mathrm{a}$ \\
Zona 2 & $1,1117 \mathrm{a}$ & $0.5331 \mathrm{a}$ & $1,6477 \mathrm{a}$ & $1,6103 \mathrm{a}$ \\
\hline Interakasi & $(-)$ & $(-)$ & $(-)$ & $(-)$ \\
\hline
\end{tabular}

Keterangan: angka yang diikuti oleh huruf yang sama pada kolom yang sama tidak berbeda nyata pada uji DMRT $\alpha 0,05$. (-) : Tidak Terjadi interaksi

Pola tumpangsari antara tanaman jagung dan kedelai dalam penelitian ini menunjukkan nilai LER dan ATER $>1$, hal ini menunjukkan bahwa sistem tumpangsari pada saat MH 1 sangat cocok dan sangat layak untuk diterapkan. Hal ini senada dengan pernyataan Hiebsch dan Mccollum (1988; Hernita, 2001; Ceunfin et al. 2015), bahwa nilai LER dan ATER > 1 menggambarkan sistem tanaman monokultur memerlukan lahan yang lebih luas dibandingkan dengan pola tumpangsari.

Mugnisjah dan Setiawan (1990; Mboeik, 2012; Ceunfin et al., 2015) menyatakan peningkatan produktivitas lahan disebabkan oleh pemilihan kombinasi tanaman dan sistem pertanaman yang tepat serta adanya hubungan atau simbiosis mutualisme antar tanaman yang ditanam secara tumpangsari. Simbiosis ini berhubungan erat dengan kebutuhan nitrogen bagi tanaman utama yang terpenuhi dari tanaman sisipan melalui kemampuannya memfiksasi nitrogen dari udara, sebaliknya tanaman sisipan memiliki toleransi terhadap naungan dapat hidup di bawah tegakan. Hosang et al. (2004; Mboeik, 2012) menyatakan kombinasi tanaman serealia dengan tanaman legum adalah kombinasi yang terbaik sebab kompetisi antar bagian tanaman dalam hal memperoleh sinar matahari dan unsur hara relatif sangat kecil.

Ratio Crowding Coefficient $(K)$ atau koefisien kepadatan relatif menunjukkan bahwa tanaman jagung tidak memberikan keuntungan sama sekali karena memiliki nilai negatif $(-)$ dan tanaman kedelai menunjukkan nilai keuntungan pada jarak tanam $90 \mathrm{~cm} \times 20 \mathrm{~cm}$ sedangkan pada jarak tanam lain dan zona ruang temu tidak menunjukkan adanya keuntungan (Tabel 2.). Hasil penelitian menunjukkan tidak adanya keuntungan pada tumpangsari bila dilihat dari koefisien kepadatan relatif. Yilmaz et al., (2007) menyatakan bahwa koefisien kepadatan relatif adalah ukuran dominasi dari suatu spesies yang ditumpangsarikan. Jika nilai $\mathrm{K} \geq 1$ terdapat keuntungan, $\mathrm{K}=1$ tidak ada keuntungan (titik impas) dan $\mathrm{K} \leq 1$ terjadi kerugian.

Aggressivity $(A)$ atau agresifitas tanaman merupakan dominasi suatu spesies tanaman dalam tumpangsari. Hasil penelitian menunjukkan bahwa tanaman jagung lebih dominan agresif terhadap tanaman kedelai baik pada perlakuan jarak tanaman maupun pada perlakuan zona ruang temu namun pada jarak tanaman $50 \mathrm{~cm} \times 20 \mathrm{~cm}$ tanaman kedelai lebih agresif daripada tanaman jagung (Tabel 2.). Keadaan demikian menunjukkan adanya dominasi tanaman jagung dalam berkompetisi untuk memperoleh sumberdaya baik secara vertikal maupun secara horizontal. Tanaman yang kuat dalam berkompetis akan memberikan hasil maksimal pada akhir siklus kehidupannya. Nilai yang tedapat pada agresifitas adalah sama namun dibedakan dengan tanda positif $(+)$ dan negatif $(-)$. Palaniappan (1985) menyatakan bahwa Jika nilai Agresivitas $(A)=0$ tanaman sama-sama kompetitif, $\mathrm{A}=+$ (positif) tanaman lebih dominan berkompetisi, $\mathrm{A}=$

\begin{tabular}{|c|c|c|c|c|c|c|c|c|c|}
\hline \multirow[b]{2}{*}{ Perlakuan } & \multicolumn{2}{|c|}{ Relative Crowding Coefficient $(\mathrm{K})$} & \multicolumn{2}{|c|}{ Aggresivity (A) } & \multicolumn{2}{|c|}{ Competitive Ratio $(R C)$} & \multicolumn{3}{|c|}{ Actual yeild loss (AYL) } \\
\hline & Jagung & Kedelai & Jagung & Kedelai & Jagung & Kedelai & Jagung & Kedelai & Total \\
\hline \multicolumn{10}{|l|}{ Jarak Tanam } \\
\hline $50 \mathrm{~cm} \times 20 \mathrm{~cm}$ & $-0,112 \mathrm{a}$ & $0,689 \mathrm{a}$ & $-0,00000536 \mathrm{a}$ & $0,00000536 \mathrm{a}$ & $1,344 \mathrm{a}$ & $1,2031 \mathrm{a}$ & $-8,318 \mathrm{a}$ & $2,419 \mathrm{a}$ & $1,587 \mathrm{a}$ \\
\hline $70 \mathrm{~cm} \times 20 \mathrm{~cm}$ & $-3,145 \mathrm{a}$ & $-0,384 \mathrm{a}$ & $0,00002492 \mathrm{a}$ & $-0,00002492 \mathrm{a}$ & $3,016 \mathrm{a}$ & $0,7242 \mathrm{a}$ & $-0,6153 a b$ & $0,592 \mathrm{a}$ & $0,052 \mathrm{a}$ \\
\hline $90 \mathrm{~cm} \times 20 \mathrm{~cm}$ & $-1,514 \mathrm{a}$ & $1,881 \mathrm{a}$ & $0,00003510 \mathrm{a}$ & $-0,00003510 a$ & $3,239 \mathrm{a}$ & $0,4952 \mathrm{a}$ & $-0,4813 \mathrm{~b}$ & $0,533 \mathrm{a}$ & $-0,024 \mathrm{a}$ \\
\hline \multicolumn{10}{|c|}{ Zona Ruang Temu } \\
\hline Zona 1 & $-0,939 \mathrm{a}$ & $0.7376 \mathrm{a}$ & $0,00001370 \mathrm{a}$ & $-0,00001370 a$ & $2,2764 \mathrm{a}$ & $0,9115 \mathrm{a}$ & $-0,64715 \mathrm{a}$ & $1,4692 \mathrm{a}$ & $0,8220 \mathrm{a}$ \\
\hline Zona 2 & $-2,241 \mathrm{a}$ & $0.7202 \mathrm{a}$ & $0,00002275 \mathrm{a}$ & $-0,00002275 \mathrm{a}$ & $2,7890 \mathrm{a}$ & $0,7034 \mathrm{a}$ & $-0,63844 \mathrm{a}$ & $0,8934 \mathrm{a}$ & $0,2549 \mathrm{a}$ \\
\hline Interakasi & $(-)$ & $(-)$ & $(-)$ & $(-)$ & $(-)$ & $(-)$ & $(-)$ & $(-)$ & $(-)$ \\
\hline
\end{tabular}
-- (negatif) tanaman kalah dalam berkompetisi.

Tabel 2. Relative Crowding Coefficient, Aggresivity, Competitive Ratio, Actual yeild loss

Keterangan: angka yang diikuti oleh huruf yang sama pada kolom yang sama tidak berbeda nyata pada uji DMRT $\alpha$ 0,05. (-) : Tidak Terjadi interaksi

Competitive Ratio (RC) atau rasio kompetisi adalah kemampuan tanaman dalam memperoleh sumberdaya baik secara vertikal maupun secara horizontal. Hasil penelitian menunjukkan bahwa rasio kompetisi tanaman jagung lebih tinggi dibandingkan dengan tanaman kedelai baik pada perlakuan jarak tanaman maupun pada zona ruang temu (Tabel 2.). Nilai rasio kompetisi menguatkan nilai agresifitas, bahwa semakin tinggi nilai agresif suatu tanaman dalam sistem tumpangsari maka semakin kuat tanaman berkompetisi dalam memperoleh sumberdaya.
Actual Yeild Loss (AYL) atau Kehilangan hasil aktual adalah proporsi kehilangan hasil atau keuntungan tanaman sela yang ditanaman secara tumpangsari bila dibandikan dengan masing-masing tanaman monokultur. Hasil penelitian menunjukkan bahwa tanaman paling banyak mengalami kehilangan hasil pada tumpangsari adalah jagung baik pada perlakuan jarak tanam $-8,31$ sampai $-0,48$ atau setara dengan $831 \%$ sampai $48 \%$ dan pada perlakuan zona ruang temu mengalami kehilangan sampai -0,63 sampai -0,64 atau setara dengan $63 \%$ sampai $64 \%$. Jarak tanam paling rapat mengalami kehilangan hasil paling 
tinggi dan zona ruang temu 1 mengalami kehilangan hasil paling tinggi. Tanaman kedelai tidak mengalami kehilangan hasil karena bernilai positif (Tabel 2.). Yilmaz et al., (2007) menyatakan bahwa tanaman kacang dengan nilai actual yield loss antara -0,42 sampai -0,02 setara dengan kehilangan hasil dari $42 \%-2 \%$ bila dibandingkan dengan monokultur. Selanjutnya Dhima et al. (2006) menyatakan bahwa tumpangsari antara tanaman vects (Visia sativa L) dengan sereal mengalami kehilangan hasil antara $-0,391$ sampai $-0,040$ yang setara dengan kehilangan hasil antara 39,1\% sampai $4 \%$.

Hasil penelitian secara keseluruhan terhadap penilaian kompetisi dan hasil tanaman pada sistem tumpangsari jagung dan kedelai menunjukkan bahwa tanaman jagung pada umumnya lebih agresif, lebih kuat dalam berkompetisi dalam memperoleh sumberdaya secara horison maupun secara vertikal, namun mengalami kehilangan hasil paling tinggi. Kehilangan hasil yang dialami oleh tanaman jagung sebabkan oleh populasi tanaman dalam unit lahan, selain itu ada kemungkinan lain yang menyebabkan kehilangan hasil pada tanaman jagung adalah adanya autoalelopati dari tanaman jagung itu sendiri dan pengaruh alelopati dari tanaman kayu putih.

Tanaman kedelai relatif tidak mengalami kehilangan hasil aktual karena memiliki nilai positif (Tabel 2.) walaupun tanaman kalah agresifitas dan memiliki nilai ratio kompetisi yang rendah namun mampu memberikan hasil yang maksimum. Satu-satu alasan tanaman kedelai mampu berproduksi dengan baik dibawah tegakan tanaman jagung dan tanaman kayu putih adalah kemampuan tanaman kedelai hidup dibawah naungan dan mampu mengelola nitrogen bebas untuk dimamfaatkan selama pengisian biji.

\section{Simpulan}

Tumpangsari tanaman jagung dan kedelai dibawah tegakan kayu putih sangat menguntungkan. Tanaman jagung lebih agresif dan competitif daripada tanaman kedelai sehingga menyumbangkan keuntungan pada land equivalent ratio total dan area time equivalent ratio dan Actual Yeild loss total pada perlakuan zona pengolahan lahan maupun jarak tanaman. Zona pengolahan lahan 0-1 $\mathrm{m}$ dari kedudukan pohon kayu putih memberikan hasil land equivalent ratio total, area time equivalent ratio, dan actual yield loss total paling tinggi yaitu sebesar 1,71, 1,66 dan 0,82 sedangkan Jarak tanam $50 \mathrm{~cm}$ x $20 \mathrm{~cm}$ memberikan hasil land equivalent ratio total, area time equivalent ratio, dan actual yield loss total paling tinggi yaitu sebesar 2,27, 2,25 dan 1,58.

\section{Pustaka}

Anil, L., Park, J., Phipps, R.H., Miller, F.A., 1998. Temperate intercropping of cereals for forage: a review of the potential for growth and utilization with particular reference to the UK. Grass Forage Sci. 53, 301-317.

Beets, W.C. 1982. Multiple Cropping and Tropical Farming System. Gower Publ Co. Chicago.

Banik, P. 1996. Evaluation of Wheat (T. aestivum) and Legume Intercropping Under 1:1 and 2:1 Row-Replacement Series System. J. Agron. Crop Sci. 176: $289-294$.

Chen, C., Westcott, M., Neill, K., Wichman, D., Knox, M., 2004. Row configuration and nitrogen application for barley-pea intercropping in Montana. Agron. J. 96, 1730-1738.

Ceunfin. S., D. Prajitno. \& P. Suryanto. 2015. Tata Kelola Tumpangsari Jagung dan Kedelai di Bawah Tegakan Kayu Putih Terhadap Hasil Kedelai. Seminar Nasional Kebijakan dan Hasil Penelitian Pertanian IV dalam Rangka Dies Natalis ke-69 Fakultas Pertanian Universitas Gadjah Mada.

Dhima K.V., A.S. Lithourgidis., I.B. Vasilakoglou.\&C.A. Dordas, 2006 Competition Indices of Common Vetch and Cereal Intercrops in Two Seeding Ratio, Elsevier.Field Crops Research 100:249-256 p. (diakses 15 Agustus 2015).

Egbe, O.M., 2010, Effects of plant density of intercropped soybean with tall sorghum on competitive ability of soybean and economic yield at Otobi, Benue State, Nigreia., Journal of Cereals and Oilseeds, 1(1), 1-10

Hernita, D., Kajian Ragam Tumpangsari Antara Labu Kuning dan Jagung., Tesis., Fakultas Pertanian Universitas Gadjah Mada, Yogyakarta

Karyawati A. S, B Waluyo \& N. Basuki, 2010 Evaluasi penampilan plasma nutfah jagung dan galur Kedelai hasil mutasi untuk tumpangsari Menggunakan ugmented design., Fakultas Pertanian Universitas Brawijaya diakses 5 Agustus 2014.

Mboik D.M., Pengaruh Kerapatan dan Jenis Kacang Dalam Sistem Tumpangsari Terhadap Pertumbuhan dan Hasil Tanaman Jagung Lokal., Skripsi Universitas Timor., Kefamenanu

Makgoga. M.W., 2013., Influence of Lablab (Lablab Purpureus) and Dry Bean (phaseolusVulgaris) Intercrops With Maize (Zea Mays l.) On Maize Grain Yield and Soil Fertility Status. a mini-dissertation submitted for the degree of master of science in agriculture (agronomy), in the department of plant production, soil science and agricultural engineering, school of agriculture and environmental sciences, faculty of science and agriculture, at the university of limpopo, south africa. Diakses 22 April 2015

Palaniappan., 1985., Cropping system in the Tropic: Prinsiples and Management., Wiley Eastern Limited and Tamil Nadu Agricultural University., Coimbataro

Suryanto, P., Tohari., dan Sabarnurdin, M.S., 2005, Dinamika Sistem Berbagi Sumberdaya (Resouces Sharing) Dalam Agroforestri: Dasar Pertimbangan Penyusunan Strategi Silvikultur, jurnal ilmu pertanian Vol. 12 No.2, 2005 :165-178. (diakses 5 agustus 2014).
Turmudi E. 2002. Kajian Pertumbuhan Dan Hasil Tanaman Dalam Sistem Tumpangsari Jagung Dengan Empat Kultivar Kedelai Pada Berbagai Waktu Tanam. Jurnal Ilmu-Ilmu Pertanian Indonesia.Volume 4, No 2, hlm. 89-96.

Yilmaz. F, M. Atak, \& M. Erayman, 2008, Identification of Advantages of Maize-Legume Intercropping over Solitary Cropping through Competition Indices in the East Mediterranean Region Turk J Agric For 32 (2008) 111119. (diakses 14 Agustus 2015). 